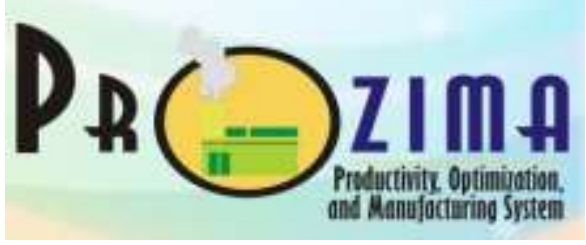

Prozima : Vol. 5, No. 2, Desember 2021, 93-99

E-ISSN. 2541-5115

Journal Homepage: http://ojs.umsida.ac.id/index.php/prozima

DOI Link: http://doi.org/10.21070/prozima.v5i2.1452

Article DOI: http://doi.org/10.21070/prozima.v5i2.1452

\title{
Policy Making in Optimizing Inventory Control with Continous and Periodic Review Method at PT. XYZ
}

\section{Pengambilan Kebijakan \\ Dalam Mengoptimalkan Pengendalian Persediaan Dengan Metode Continuous dan Periodic Review di PT. XYZ}

\author{
Reka Nur Aini ${ }^{1}$, Enny Aryanny ${ }^{2}$ \\ ${ }^{1,2}$ Program Studi Teknik Industri, Fakultas Teknik, Universitas Pembangunan \\ Nasional "Veteran" Jawa Timur \\ e-mail:rekanuraini06@gmail.com ${ }^{1}$, enny.ti@upnjatim.ac.id ${ }^{2}$
}

\begin{abstract}
PT. XYZ is a company enganged in the garment sector that produces office uniforms, polo t-shirts and $t$ shirts with the highest demand for polo t-shirt products from Lacoste 20S Black cloth. Based on company data and the results of interviews with informants, it found that companies often eperience stockout and overstock of supplies of Lacoste $20 \mathrm{~S}$ black cloth due to fluctuating demand. This study to control inventory by comparing the company method with the method of Continuous Review $(s, S)$ System, $(S, Q)$ System and Periodic Review $(R, s, S)$ System, $(R, S)$ System to obtain minimum total cost of inventory. Based on the calculation using the company method, the total cost of inventory is $R p 643.487 .400$ and the minimum total cost of inventory is carried out using the Continuous Review $(s, Q)$ System method is $R p$ 635.880.585 so that experiences savings of $R p$ 7.606.815 with the percentage of cost reduction is 1,18\%. The forecasting needs for April 2021 to March 2022 using the Continuous Review (s,Q) System method, the order quantity is $378 \mathrm{Kg}$ and the reorder point is $133 \mathrm{Kg}$ with a total inventory cost is Rp 767.415.089.
\end{abstract}

Keywords : Continuous Reviews, Fluctuating Demand, Periodic, Inventory

\begin{abstract}
ABSTRAK
PT. XYZ merupakan perusahaan yang bergerak di bidang garmen yang memproduksi jenis produk seragam kantor, polo t-shirt dan t-shirt dengan permintaan tertinggi pada produk polo t-shirt bahan kain Lacoste $20 \mathrm{~S}$ Hitam. Berdasarkan data perusahaan dan hasil wawancara dengan narasumber, didapatkan informasi bahwa perusahaan sering mengalami kelebihan dan kekurangan persediaan kain Lacoste 20S Hitam karena adanya permintaan yang fluktuatif. Penelitian ini bertujuan untuk melakukan pengendalian persediaan dengan membandingkan metode perusahaan dengan metode Continuous Review(s,S) System,(s, Q) System dan Periodic Review $(R, s, S)$ System, $(R, S)$ System untuk memperoleh total biaya persediaan yang paling minimum. Berdasarkan perhitungan dengan menggunakan metode perusahaan diperoleh total biaya persediaan sebesar $R p$ 643.487.400 dan total biaya persediaan yang paling minimum dilakukan dengan menggunakan metode Continuous Review ( $s, Q$ ) System yaitu sebesar Rp 635.880.585 sehingga mengalami penghematan sebesar Rp 7.606.815 dengan persentase penurunan biaya sebesar 1,18\%. Kemudian dilakukan peramalan kebutuhan bulan April 2021 sampai Maret 2022 menggunakan metode Continuous Review (s,Q) System didapatkan jumlah pemesanan sebesar $378 \mathrm{Kg}$ dan titik pemesanan kembali sebesar $133 \mathrm{Kg}$ dengan total biaya persediaan sebesar Rp 767.415.089.
\end{abstract}

Kata Kunci : Continuous Reviews, Permintaan Fluktuatif, Periodik, Persediaan

\section{PENDAHULUAN}

Dalam rangka mempertahankan pertumbuhan dan berkembangnya perusahaan maka perusahaan perlu melakukan perencanaan dan pengendalian persediaan terhadap berbagai macam peralatan dan material pendukung. Menurut Syamil et al (2018) metode Continuous Review merupakan metode yang mengendalikan tingkat persediaan secara terus menerus sedangkan metode Periodic Review permintaan dikendalikan dalam interval waktu dengan jumlah pemesanan yang tetap. Persediaan merupakan kekayaan perusahaan yang berperan penting dalam operasi bisnis, sehingga perusahaan perlu melakukan perencanaan dan pengendalian

Pengambilan Kebijakan dalam Mengoptimalkan Pengendalian Persediaan dengan Metode Continous dan Periodic Review di PT. XYZ / Reka Nur Aini, Enny Aryanny

Peer reviewed under responsibili of Universitas Muhammadiyah Sidoarjo.

(C) 2021 Universitas Muhammadiyah Sidoarjo. All Right reserved. This is an open access article under the CC BY licence (http://creativecommons.org/licences/by/4.0/) 
persediaan agar proses produksi dalam perusahaan dapat berjalan dengan lancar sehingga dapat meminimasi total biaya persediaan (Putri, 2019). PT. XYZ merupakan perusahaan yang bergerak dibidang garmen yang memproduksi jenis produk seragam kantor, polo $t$-shirt dan $t$-shirt dengan permintaan tertinggi pada produk polo $t$-shirt pada bahan kain Lacoste 20S Hitam. Dari data perusahaan dan wawancara diperoleh bahwa perusahaan sering mengalami kelebihan dan kekurangan persediaan kain Lacoste 20S Hitam dikarenakan adanya permintaan yang fluktuatif sehingga menyebabkan ketersediaan kain di gudang tidak sesuai dengan kebutuhan. Dari ulasan di atas, maka dilakukan penelitian untuk menyelesaikan permasalahan tersebut yaitu dengan melakukan pengendalian persediaan pada perusahaan garmen menggunakan metode Continuous Review $(s, S)$ System, $(s, Q)$ System dan Periodic Review $(R, s, S)$ System, $(R, S)$ System dalam melakukan perencanaan persediaan yang optimal sehingga dapat meminimumkan total biaya persediaan serta dapat mengantisipasi adanya kelebihan maupun kekurangan stok yang tersedia (Ayanny, 2020). Metode tersebut akan digunakan untuk membandingkan total biaya persediaan yang dikeluarkan oleh perusahaan dan kemudian dipilih total biaya persediaan yang paling minimum, sehingga biaya persediaan yang optimal dapat diterapkan oleh perusahaan dan biaya yang berkaitan dengan persediaan dapat ditekan.

\section{METODE}

Pada tahap ini diuraikan secara singkat mengenai langkah-langkah yang akan digunakan untuk memecahkan masalah. Berikut adalah tahapan atau langkah-langkah dalam penelitian untuk penyelesaian masalah:

1. Mengumpulkan data dan informasi untuk menyelesaikan permasalahan. Data tersebut adalah jumlah kebutuhan kain, biaya pembelian, biaya pesan, biaya simpan dan data lead time pemesanan kain Lacoste $20 \mathrm{~S}$ Hitam bulan April 2020-Maret 2021.

2. Pengolahan data pada penelitian ini terbagai menjadi dua yaitu pengolahan data dengan metode perusahaan dan dengan menggunakan metode usulan yaitu Continuous Review $(s, S)$ System, $(s, Q)$ System dan Periodic Review $(R, s, S)$ System, $(R, S)$ System.

3. Menghitung total biaya persediaan kain Lacoste $20 S$ Hitam yang dikeluarkan oleh perusahaan dan menggunakan metode usulan.

4. Membandingkan total biaya persediaan yang telah dihitung dengan metode perusahaan dan metode usulan. Maka didapatkan mana yang menghasilkan total biaya persediaan yang paling minimum. Dan dihitung nilai efisiensinya.

5. Melakukan peramalan persediaan dengan menggunakan metode usulan.

6. Menarik analisa dari perhitungan yang didapat dan membuat analisa bagaimana sebaiknya mengoptimalkan perencanaan dan pengendalian persediaan kain Lacoste $20 \mathrm{~S}$ Hitam.

\section{HASIL DAN PEMBAHASAN}

A. Metode Perusahaan

$$
\begin{aligned}
& \text { Biaya Pembelian }(\quad ） \quad=4.778 \mathrm{Kg} \times \mathrm{Rp} 130.000=\mathrm{Rp} 621.140 .000 / \mathrm{Tahun} \\
& \text { Biaya Pemesanan }(\quad) \quad=4 \times \text { Rp } 350.000=\text { Rp 1.400.000/Tahun } \\
& \text { Biaya Simpan }(\quad) \quad=509 \mathrm{Kg} \times \mathrm{Rp} 28.600=\mathrm{Rp} 14.557 .400 / \text { Tahun } \\
& \text { Biaya Kekurangan }(\quad ＼quad=142 \mathrm{Kg} \text { x Rp } 45.000=\mathrm{Rp} 6.390 .000 / \text { Tahun }
\end{aligned}
$$

Total biaya persediaan menggunakan metode perusahaan adalah sebagai berikut:

$$
\begin{aligned}
& =\operatorname{Rp} 621.140 .000+\operatorname{Rp} 1.400 .000+\operatorname{Rp} 14.557 .400+\operatorname{Rp} 6.390 .0000 \\
& =\operatorname{Rp} 643.487 .400 / \text { Tahun }
\end{aligned}
$$

B. Metode Continuous Review $(s, S)$

Maka perhitungan rata-rata dan standar deviasi:

$$
\begin{aligned}
& ={ }^{\Sigma}=\longrightarrow 399 \mathrm{Kg} \\
& =\sqrt{\bar{\sum}} \sqrt{ }=611,67 \mathrm{Kg}
\end{aligned}
$$

Pengambilan Kebijakan dalam Mengoptimalkan Pengendalian Persediaan dengan Metode Continous dan Periodic Review di PT. XYZ / Reka Nur Aini, Enny Aryanny

Peer reviewed under responsibili of Universitas Muhammadiyah Sidoarjo.

(C) 2021 Universitas Muhammadiyah Sidoarjo. All Right reserved. This is an open access article under the CC BY licence (http://creativecommons.org/licences/by/4.0/) 


\section{Iterasi 1}

1. Hitung ukuran lot pemesanan ( )

$$
=\sqrt{-}=\sqrt{ }=342 \mathrm{Kg}
$$

2. Hitung besarnya nilai kemungkinan kekurangan persediaan ( )

$$
=\longrightarrow=\longrightarrow, 0435
$$

Dengan nilai sebesar 0,0435 maka nilai sebesar 1,7121

3. Hitung titik pemesanan kembali ( )

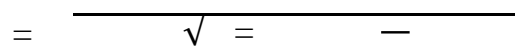

$$
(\sqrt{-})=267 \mathrm{Kg}
$$

4. Hitung nilai ( )

Dengan nilai yaitu 0,0921 dan nilai

$$
=[\quad]=-[\quad]=0,9296 \mathrm{Kg}
$$

Perhitungan nilai adalah sebagai berikut:

$=\sqrt{{ }^{*} \int(\quad)++}=\sqrt{ }=362 \mathrm{Kg}$

5. Hitung besarnya nilai kemungkinan kekurangan persediaan ( )

$$
=\longrightarrow=0,0459 \rightarrow \quad=1,6863
$$

6. Hitung titik pemesanan kembali ( )

$$
=\quad \sqrt{ }=\quad-\quad(\sqrt{-})=265 \mathrm{Kg}
$$

7. Hasil nilai $=267 \mathrm{Kg}$ dan hasil $=265 \mathrm{Kg}$ tidak sama. Maka, iterasi dilanjutkan.

\section{Iterasi 2}

1. Hitung nilai $(\quad)$

Dengan nilai yaitu 0,0963 dan nilai yaitu 0,0189 , didapatkan nilai $\mathrm{N}$ adalah:

$$
=[\quad]=-[\quad]=0,8946 \mathrm{Kg}
$$

Perhitungan nilai adalah sebagai berikut:

$$
=\sqrt{L}^{*} \int(\quad)++\sqrt{ }=\sqrt{ }=362 \mathrm{Kg}
$$

2. Hitung kembali nilai ( )

$$
=\longrightarrow=0,0459 \rightarrow=1,6863
$$

3. Hitung titik pemesanan kembali ( )

$$
=\quad \sqrt{ }=\quad-\quad(\sqrt{-})=265 \mathrm{Kg}
$$

4. Hasil nilai $=265 \mathrm{Kg}$ dan hasil $=265 \mathrm{Kg}$ sama. Maka, iterasi selesai.

Formulasi total biaya persediaan metode Continuous Review $(s, S)$
a. Biaya Pembelian $(\quad) \quad=4.778 \mathrm{Kg} \times \mathrm{Rp} 130.000=\mathrm{Rp} 621.140 .000 /$ Tahun
b. Biaya Pemesanan $(\quad) \quad==\operatorname{Rp~4.619.613/Tahun~}$

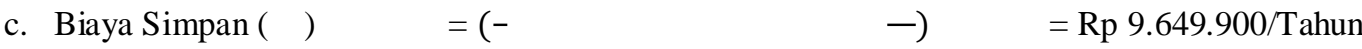
d. Biaya Kekurangan $(\quad)=(-\quad) \quad$ Rp 556.905/Tahun
e. Total Biaya Persediaan $=\operatorname{Rp} 621.140 .000+\operatorname{Rp} 4.619 .613+\mathrm{Rp} 9.649 .900+\operatorname{Rp} 556.905$
$=\operatorname{Rp} 635.966 .419 /$ Tahun

Pengambilan Kebijakan dalam Mengoptimalkan Pengendalian Persediaan dengan Metode Continous dan Periodic Review di PT. XYZ / Reka Nur Aini, Enny Aryanny

Peer reviewed under responsibili of Universitas Muhammadiyah Sidoarjo.

(C) 2021 Universitas Muhammadiyah Sidoarjo. All Right reserved. This is an open access article under the CC BY licence (http://creativecommons.org/licences/by/4.0/) 
C. Metode Continuous Review $(s, Q)$

\section{Iterasi 1}

1. Hitung ukuran lot pemesanan ( )

$$
=\sqrt{-}=\sqrt{-}=342 \mathrm{Kg}
$$

2. Hitung besarnya nilai kemungkinan kekurangan persediaan ( )

$$
=\longrightarrow=0,0455 \rightarrow \quad=1,6909
$$

3. Hitung titik pemesanan kembali ( )

$$
=\sqrt{ }=\quad-\quad(\sqrt{-})=265 \mathrm{Kg}
$$

4. Hitung nilai ( )

Dengan nilai yaitu 0,0955 dan nilai yaitu 0,0187 , didapatkan nilai $\mathrm{N}$ adalah :

$$
=[\quad]=-[\quad]=0,8877 \mathrm{Kg}
$$

Perhitungan nilai adalah sebagai berikut:

$$
=\sqrt{L}{ }^{*} \int(\quad)++\sqrt{ }=361 \mathrm{Kg}
$$

5. Hitung besar nilai kemungkinan kekurangan persediaan ( )

$$
=-=0,0480 \rightarrow=1,6651
$$

6. Hitung titik pemesanan kembali ( )

$$
=\quad \sqrt{ }=\quad-\quad(\sqrt{-})=263 \mathrm{Kg}
$$

7. Hasil nilai $=265 \mathrm{Kg}$ dan hasil $=263 \mathrm{Kg}$ tidak sama. Maka, iterasi dilanjutkan.

Iterasi 2

1. Hitung nilai $(\quad)$

Dengan nilai yaitu 0,0970 dan nilai yaitu 0,0198, didapatkan nilai $\mathrm{N}$ adalah :

$$
=[\quad]=-[\quad]=0,8895 \mathrm{Kg}
$$

Perhitungan nilai adalah sebagai berikut:

$$
=\sqrt{{ }^{*} \int(\quad)+}=\sqrt{ }=361 \mathrm{Kg}
$$

2. Hitung kembali nilai ( )

$$
=-==0,0480 \rightarrow=1,6640
$$

3. Hitung titik pemesanan kembali ( )

$$
=\quad \sqrt{ }=\quad-\quad(\sqrt{-})=263 \mathrm{Kg}
$$

4. Hasil nilai $=2633 \mathrm{Kg}$ dan hasil $=263 \mathrm{Kg}$ sama. Maka, iterasi selesai.

Formulasi total biaya persediaan metode Continuous Review $(s, Q)$

a. Biaya Pembelian $(\quad) \quad=4.778 \mathrm{Kg} \times \mathrm{Rp} 130.000=\mathrm{Rp} 621.140 .000 /$ Tahun

b. Biaya Pemesanan $(\quad) \quad==$ Rp 4.632.410/Tahun

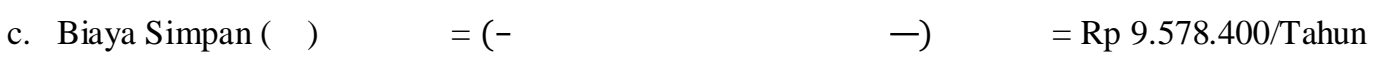

d. Biaya Kekurangan $(\quad) \quad=(\longrightarrow)=\operatorname{Rp~529.775/Tahun~}$

e. Total Biaya Persediaan $=\operatorname{Rp~} 621.140 .000+\operatorname{Rp} 4.632 .410+$ Rp $9.578 .400+\operatorname{Rp} 529.775$

$=\operatorname{Rp} 635.880 .585 /$ Tahun

Pengambilan Kebijakan dalam Mengoptimalkan Pengendalian Persediaan dengan Metode Continous dan Periodic Review di PT. XYZ / Reka Nur Aini, Enny Aryanny

Peer reviewed under responsibili of Universitas Muhammadiyah Sidoarjo.

(C) 2021 Universitas Muhammadiyah Sidoarjo. All Right reserved. This is an open access article under the CC BY licence (http://creativecommons.org/licences/by/4.0/) 
D. Metode Periodic Review $(R, s, S)$

\section{Iterasi 1}

1. Hitung interval waktu pemesanan ( )

$$
=\sqrt{-}=\sqrt{-}=0,072 \text { Tahun }
$$

2. Hitung besar nilai kemungkinan kekurangan persediaan ( )

$$
=-=\longrightarrow=0,0455 \rightarrow=1,6909
$$

3. Hitung persediaan maksimum ( )

$$
=\quad \sqrt{ }=(-) \quad\left(\sqrt{{ }^{-}}=769 \mathrm{Kg}\right.
$$

4. Formulasi total biaya persediaan metode Periodic Review $(R, s, S)$

Dengan nilai yaitu 0,0955 dan nilai yaitu 0,0187 , didapatkan nilai adalah :

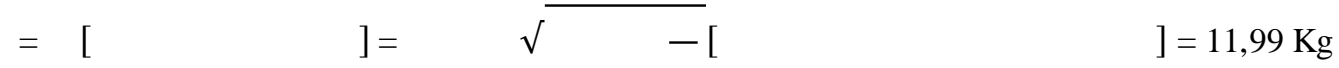

Total Biaya Persediaan

\section{Iterasi 2}

$$
\begin{aligned}
& =\quad-(-)-(-) \\
& =\operatorname{Rp} \overline{657.349 .163 / \text { Tahun }}
\end{aligned}
$$

Dengan nilai sebesar 0,072 maka akan dicoba dengan penambahan nilai sebesar - periode yaitu 0,0358, sehingga nilai $=0,1074$. Selanjutnya dilakukan perhitungan kembali ke langkah 2 . Diperoleh total biaya persediaan sebesar Rp 663.852.275/Tahun.

Iterasi 3

Dengan nilai sebesar 0,072 maka akan dicoba dengan pengurangan nilai sebesar - periode yaitu 0,0358, sehingga nilai $=0,0358$. Selanjutnya dilakukan perhitungan kembali ke langkah 2 . Diperoleh total biaya persediaan sebesar Rp 653.603.674/ Tahun.

\section{Iterasi 4}

Dengan nilai sebesar 0,072 maka akan dicoba dengan pengurangan nilai sebesar - periode yaitu 0,0179, sehingga nilai $\quad=0,0537$. Selanjutnya dilakukan perhitungan kembali ke langkah 2 . Diperoleh total biaya persediaan sebesar $\mathrm{Rp}$ 654.730.439/Tahun. Iterasi tidak dilanjutkan karena total biaya persediaan yang dihasilkan pada iterasi ke empat lebih besar dibandingkan dengan hasil iterasi ke tiga.

E. Metode Periodic Review $(R, S)$

\section{Iterasi 1}

1. Hitung interval waktu pemesanan ( )

$$
=\sqrt{-}=\sqrt{-}=0,072 \text { Tahun }
$$

2. Hitung besar nilai kemungkinan kekurangan persediaan ( )

$$
=\longrightarrow=\longrightarrow, 043 \lessgtr \quad=1,7121
$$

3. Hitung persediaan maksimum ( )

$$
=\quad \sqrt{ }=\quad(\quad-) \quad \sqrt{{ }^{-}}=773 \mathrm{Kg}
$$

4. Formulasi total biaya persediaan metode Periodic Review $(R, s, S)$
Dengan nilai yaitu 0,0921 dan nilai yaitu 0,0178 , didapatkan nilai $\mathrm{N}$ adalah :

$$
=[
$$$$
]=
$$$$
\sqrt{-[}
$$$$
]=11,58 \mathrm{Kg}
$$

Pengambilan Kebijakan dalam Mengoptimalkan Pengendalian Persediaan dengan Metode Continous dan Periodic Review di PT. XYZ / Reka Nur Aini, Enny Aryanny

Peer reviewed under responsibili of Universitas Muhammadiyah Sidoarjo. 
Total Biaya Persediaan

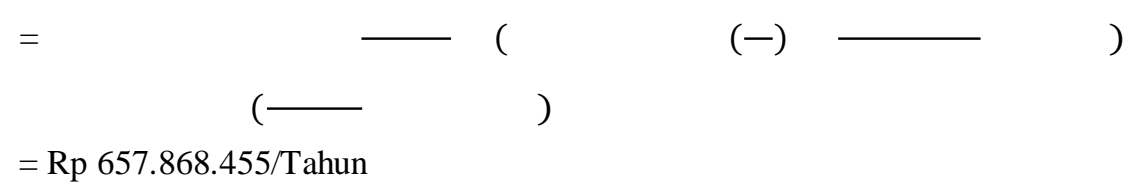

\section{Iterasi 2}

Dengan nilai sebesar 0,072 maka akan dicoba dengan penambahan nilai sebesar - periode yaitu 0,0358, sehingga nilai $\quad=0,1074$. Selanjutnya dilakukan perhitungan kembali ke langkah 2 . Diperoleh total biaya persediaan sebesar Rp 664.711.640/Tahun.

\section{Iterasi 3}

Dengan nilai sebesar 0,072 maka akan dicoba dengan pengurangan nilai sebesar - periode yaitu 0,0358, sehingga nilai $=0,0358$. Selanjutnya dilakukan perhitungan kembali ke langkah 2 . Diperoleh total biaya persediaan sebesar Rp 653.844.282/Tahun.

\section{Iterasi 4}

Dengan nilai sebesar 0,072 maka akan dicoba dengan pengurangan nilai sebesar - periode yaitu 0,0179, sehingga nilai $=0,0537$. Selanjutnya dilakukan perhitungan kembali ke langkah 2 . Diperoleh total biaya persediaan sebesar Rp 655.110.321/ Tahun.

Iterasi tidak dilanjutkan karena total biaya persediaan yang dihasilkan pada iterasi ke empat lebih besar dibandingkan dengan hasil iterasi ke tiga. Perbandingan total biaya persediaan kain Lacoste 20S Hitam untuk masing-masing metode terdapat pada Tabel 1.

TABEL 1

PERBANDINGAN TOTAL BIAYA PERSEDIAAN METODE CONTINUOUS REVIEW $(s, S) S Y S T E M,(s, Q)$ SYSTEM DAN PERIODIC REVIEW $(R, s, S)$ SYSTEM, $(R, S)$ SYSTEM

\begin{tabular}{ccccc}
\hline & $\begin{array}{c}\text { Metode Continuous Review } \\
(s, S)\end{array}$ & $\begin{array}{c}\text { Metode Continuous Review } \\
(s, Q)\end{array}$ & $\begin{array}{c}\text { Metode Periodic Review } \\
(R, s, S)\end{array}$ & $\begin{array}{c}\text { Metode Periodic Review } \\
(R, S)\end{array}$ \\
\hline $\begin{array}{c}\text { Total Biaya } \\
\text { Persediaan }\end{array}$ & $\mathrm{Rp} 635.966 .419$ & $\mathrm{Rp} 635.880 .585$ & $\mathrm{Rp} 653.603 .674$ & $\operatorname{Rp} 653.844 .282$ \\
\hline
\end{tabular}

Pada Tabel I, total biaya persediaan dengan menggunakan metode Continuous Review (s, Q) System memberikan total biaya persediaan kain Lacoste 20S Hitam yang lebih minimum yaitu sebesar Rp 635.880.585.Selanjutnya, total biaya persediaan dengan metode Continuous Review (s,Q) System akan dibandingkan dengan metode perusahaan seperti pada Tabel 2.

TABEL 2

PERBANDINGAN TOTAL BIAYA PERSEDIAAN METODE CONTINUOUS REVIEW (s,Q) SYSTEM DENGAN METODE PERUSAHAAN

\begin{tabular}{ccc}
\hline & Metode Continuous Review $(s, Q)$ & Metode Perusahaan \\
\hline Total Biaya Persediaan & $\operatorname{Rp~635.880.585~}$ & $\mathrm{Rp} \mathrm{643.487.400}$ \\
\hline
\end{tabular}

Persentase Penurunan Biaya $=$

$$
=1,18 \%
$$

Metode Continuous Review $(s, Q)$ memberikan total biaya persediaan yang lebih minimum dari metode perusahaan dengan persentase penurunan biaya sebesar $1,18 \%$.

Hasil peramalan kebutuhan kain Lacoste 20S Hitam April 2021-Maret 2022 pada Tabel 3

TABEL 3

HASIL PER AMALAN KEBUTUHAN KAIN LACOSTE 20S HITAM APRIL 2021-MARET 2022

\begin{tabular}{cc}
\hline & Kebutuhan $(\mathrm{Kg})$ \\
\hline Kain Lacoste 20S Hitam & 5.820 \\
\hline
\end{tabular}

Berdasarkan Tabel 3 maka perhitungan rata-rata dan standar deviasi:

Pengambilan Kebijakan dalam Mengoptimalkan Pengendalian Persediaan dengan Metode Continous dan Periodic Review di PT. XYZ / Reka Nur Aini, Enny Aryanny

Peer reviewed under responsibili of Universitas Muhammadiyah Sidoarjo.

(C) 2021 Universitas Muhammadiyah Sidoarjo. All Right reserved. This is an open access article under the CC BY licence (http://creativecommons.org/licences/by/4.0/) 


$$
\begin{aligned}
=\Sigma & =\longrightarrow=485 \mathrm{Kg} \\
= & \sqrt{\Sigma}=\sqrt{\Sigma}=0 \mathrm{Kg}
\end{aligned}
$$

\section{Iterasi 1}

1. Hitung ukuran lot pemesanan ( )

$$
=\sqrt{-}=\sqrt{\longrightarrow}=378 \mathrm{Kg}
$$

2. Hitung besarnya nilai kemungkinan kekurangan persediaan ( )

$$
=-=\longrightarrow=1,7409
$$

3. Hitung titik pemesanan kembali ( )

$$
\left.=\frac{\sqrt{ }=\quad-}{(\sqrt{-}}\right)=133 \mathrm{Kg}
$$

4. Hitung nilai $(\quad)$

Dengan nilai yaitu 0,0877 dan nilai yaitu 0,0166 , didapatkan nilai $\mathrm{N}$ adalah :

$$
=[\quad]=-[\quad]=0 \mathrm{Kg}
$$

Perhitungan nilai adalah sebagai berikut:

$$
=\sqrt{{ }^{*} \int(\quad)+}=\sqrt{ }=378 \mathrm{Kg}
$$

5. Hitung besar nilai kemungkinan kekurangan persediaan ( )

$$
=\longrightarrow=0,0413 \rightarrow=1,7339
$$

6. Hitung titik pemesanan kembali ( )

$$
=\quad \sqrt{ }=\quad-\quad(\sqrt{-})=133 \mathrm{Kg}
$$

7. Hasil nilai $=133 \mathrm{Kg}$ dan hasil $=133 \mathrm{Kg}$ sama. Maka, iterasi selesai.

Formulasi total biaya persediaan metode Continuous Review $(s, Q)$

$$
\begin{aligned}
& \text { a. Biaya Pembelian }(\quad) \quad=5.820 \mathrm{Kg} \times \mathrm{Rp} 130.000=\mathrm{Rp} 756.600 .000 / \text { Tahun } \\
& \text { b. Biaya Pemesanan }(\quad) \quad=-=\text { Rp 5.388.889/Tahun }
\end{aligned}
$$

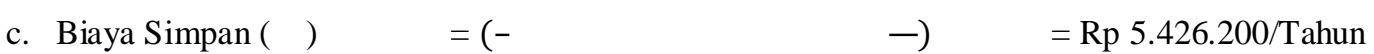

$$
\begin{aligned}
& \text { d. Biaya Kekurangan }(\quad)=(-)=\operatorname{Rp} 0 / \text { Tahun } \\
& \text { e. Total Biaya Persediaan }=\operatorname{Rp} 756.600 .000+\text { Rp 5.388.889+ Rp 5.426.200+ Rp } 0 \\
& =\operatorname{Rp} 767.415 .089 / \text { Tahun }
\end{aligned}
$$

Total biaya persediaan kain Lacoste 20S Hitam bulan April 2021-Maret 2022 menggunakan metode Continuous Review $(s, Q)$ sebesar Rp 767.415.089/Tahun dengan jumlah pemesanan sebesar $378 \mathrm{Kg}$ dan titik pemesanan kembali sebesar $133 \mathrm{Kg}$.

Adapun hasil dari perhitungan yang telah dianalisis di atas, maka didapatkan pembahasan sebagai berikut:

1. Dapat diketahui total biaya persediaan yang dikeluarkan menggunakan metode Continuous Review (s,S) System, (s,Q) System dan Periodic Review (R,s,S) System, (R,S) System pada bulan April 2020 sampai dengan Maret 2021. Total biaya persediaaan dengan menggunakan metode Continuous Review (s,S) adalah sebesar Rp Rp 635.966.419, Continuous Review (s,Q) sebesar Rp 635.880.585 dan Periodic Review (R,s,S) sebesar Rp 653.603.674, Periodic Review (R,S) sebesar Rp 653.844.282. Sehingga dapat disimpulkan bahwa metode Continuous Review (s,Q) System memberikan total biaya persediaan kain Lacoste $20 S$ Hitam yang lebih minimum.. Maka, metode Continuous Review $(s, Q)$ System dipilih untuk dilakukan perbandingan total biaya persediaan dengan metode perusahaan.

2. Dapat diketahui bahwa total biaya persediaan dengan metode perusahaan $\left(\mathrm{TC}_{\mathrm{A}}\right)$ sebesar $\mathrm{Rp} 643.487 .400$ dan total biaya persediaan metode Continuous Review (s, Q) System $\left(\mathrm{TC}_{\mathrm{B}}\right)$ sebesar Rp 635.880.585. Dari hasil perhitungan dapat diketahui bahwa metode Continuous Review $(s, Q)$ System memberikan total biaya

Pengambilan Kebijakan dalam Mengoptimalkan Pengendalian Persediaan dengan Metode Continous dan Periodic Review di PT. XYZ / Reka Nur Aini, Enny Aryanny

Peer reviewed under responsibili of Universitas Muhammadiyah Sidoarjo.

(C) 2021 Universitas Muhammadiyah Sidoarjo. All Right reserved. This is an open access article under the CC BY licence (http://creativecommons.org/licences/by/4.0/) 
Prozima : Vol. 5, No. 2, Desember 2021, 93-99

E-ISSN. 2541-5115

Journal Homepage: http://ojs.umsida.ac.id/index.php/prozima

DOI Link: http://doi.org/10.21070/prozima.v5i2.1390

Article DOI: http://doi.org/10.21070/prozima.v5i2.1390

persediaan kain Lacoste 20S Hitam yang lebih minimum dari metode perusahaan dengan penurunan biaya sebesar Rp 7.606.815. Sehingga metode Continuous Review (s,Q) System digunakan untuk perhitungan peramalan.

3. Dengan menggunakan metode Continuous Review $(s, Q)$ System dilakukan perhitungan peramalan kebutuhan kain Lacoste 20S Hitam untuk bulan April 2021-Maret 2022. Dengan demikian diperoleh perhitungan total biaya persediaan kain Lacoste 20S Hitam bulan April 2021 sampai dengan Maret 2022 menggunakan metode Continuous Review (s, $Q$ ) sebesar Rp 767.415.089/Tahun dengan jumlah pemesanan sebesar $378 \mathrm{Kg}$ dan titik pemesanan kembali (reorder point) sebesar $133 \mathrm{Kg}$.

\section{SIMPULAN}

Didapatkan pengendalian persediaan kain Lacoste 20S Hitam pada bulan April 2020-Maret 2021 dengan total biaya persediaan menggunakan metode perusahaan sebesar Rp 643.487 .400 dan total biaya persediaan yang paling minimum dilakukan dengan menggunakan metode Continuous Review (s,Q) System sebesar Rp 635.880.585 dengan penghematan biaya sebesar Rp 7.606.815 serta persentase penurunan biaya sebanyak $1,18 \%$. Setelah dilakukan perhitungan peramalan untuk kebutuhan kain Lacoste 20S Hitam bulan April 2021Maret 2022 menggunakan metode Continuous Review $(s, Q)$ System, didapatkan pengendalian persediaan kain Lacoste 20S Hitam dengan jumlah pemesanan sebesar $378 \mathrm{Kg}$ dan titik pemesanan kembali sebesar $133 \mathrm{Kg}$ dengan total biaya persediaan sebesar Rp 767.415.089.

\section{DAFTAR PUSTAKA}

[1] Ariyani, Enny. 2010, Sistem Produksi. Penerbit : Yayasan Humaniora, Yogyakarta.

[2] Aryanny, Enny dan Kurniawan, Yusuf D. 2020, “Analisis Pengendalian Persediaan Suku Cadang Housing Gowl For Gravel Pump Warman Dengan Metode Periodic Review dan Continuous Review Pada PT. XYZ”, Journal OF Industrial Engineering and Management. Vol 15, No. 01, pp. 2656-6109.

[3] Putri, Dian Alika. 2019, "Perencanaan Persediaan Untuk Mengatasi Stockout Spare Part Toner DC 286/AP405i/5010 (Super) Pada PT. Trimulia Nugraha", Skripsi. Politeknik Akademi Pimpinan Perusahaan (APP) Kementrian Perindustrian, Jakarta.

[4] Syamil, R Avicenna, Ridwan, A Yanuar dan Santosa, Budi. 2018, "Penentuan Kebijakan Persediaan Produk Kategori Food dan Non Food Dengan Menggunakan Metode Continuous Review $(s, S)$ System dan $(s, Q)$ System di PT. XYZ Untuk Optimasi Biaya Persediaan”, Jurnal Integrasi Sistem Industri. Vol 5, No. 1, pp. 49-55.

Pengambilan Kebijakan dalam Mengoptimalkan Pengendalian Persediaan dengan Metode Continous dan Periodic Review di PT. XYZ / Reka Nur Aini, Enny Aryanny

Peer reviewed under responsibili of Universitas Muhammadiyah Sidoarjo.

(C) 2021 Universitas Muhammadiyah Sidoarjo. All Right reserved. This is an open access article under the CC BY licence (http://creativecommons.org/licences/by/4.0/) 